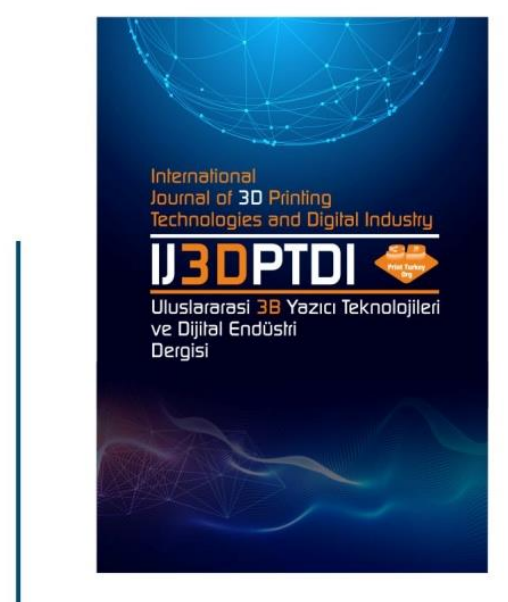

ULUSLARARASI 3B YAZICI TEKNOLOJILERI

VE DIJITAL ENDÜSTRI DERGISI

INTERNATIONAL JOURNAL QF 30 PRINTING TECHNQLOGIES AND DIGITAL INDUSTRY

I5SN:2602-3350 [Online]

URL: https://dergipark.org.tr/ij3dptdi

\title{
COMPRESSIVE STRENGTH OF DLP 3D PRINTED VARIOUS MICRO LATTICES FOR BONE TISSUE ENGINEERING
}

Yazarlar (Authors): Muhammed Enes Dokuz ${ }^{(\mathbb{} *}$, Mustafa Aydin ${ }^{(\mathbb{D}}$, Mesut Uyaner(D)

Bu makaleye şu şekilde atıfta bulunabilirsiniz (To cite to this article): Dokuz M.E., Aydin M., Uyaner M. "Compressive Strength Of Dlp 3d Printed Various Micro Lattices For Bone Tissue Engineering" Int. J. of 3D Printing Tech. Dig. Ind., 5(3): 361-371, (2021). 


\title{
COMPRESSIVE STRENGTH OF DLP 3D PRINTED VARIOUS MICRO LATTICES FOR BONE TISSUE ENGINEERING
}

\author{
Muhammed Enes Dokuz ${ }^{\mathrm{a}}$ (D), Mustafa Aydin ${ }^{\mathrm{a}, \mathrm{b}}$ (D), Mesut Uyanerc ${ }^{\text {(iD }}$ \\ ${ }^{a}$ Manisa Celal Bayar University, Hasan Ferdi Turgutlu Technology Faculty, Mechanical Engineering \\ Department, TURKEY \\ ${ }^{\text {b} K u ̈ t a h y a ~ D u m l u p i n a r ~ U n i v e r s i t y, ~ M e c h a n i c a l ~ E n g i n e e r i n g ~ D e p a r t m e n t, ~ T U R K E Y ~}$ \\ ${ }^{c}$ Konya Necmettin Erbakan University, Faculty of Aviation and Space Sciences, Aeronautical Engineering \\ Department, TURKEY \\ *Corresponding Author: muhammed.dokuz@cbu.edu.tr
}

(Received: 09.06.2021; Revised: 14.07.2021; Accepted: 06.09.2021)

\begin{abstract}
This study aims to design and manufacture different lattices and evaluate their success in terms of compression strength. Structures with a high surface area to volume (SA:V) ratio and macroporosity are designed to mimic cancellous bone tissue. The volume-centered cubic and face-centered cubic lattice structures are higher in terms of the SA:V ratio among the designed specimens. Tri Calcium Phosphate (TCP) and Hydroxyapatite (HA) powders, which are calcium phosphates used in healing, growth and adhesion of bone tissues, were used in the specimens. Specimens in the cylindrical form used with four different lattices were successfully produced by 3D (Digital Light Processing) DLP printing. A preliminary evaluation of the lattices was made by searching for the lowest stress and displacement values under compression load with finite element analysis. The lowest von-Mises stress value was 6.37 $\mathrm{MPa}$ in the simple cubic lattice structure. The compression test was carried out under quasi-static conditions with equal preloading. The loads at onset damage were compared. The highest fracture average load was in face-centered cubic lattice structures with $10.14 \mathrm{kN}$. Among the specimens with low standard deviation in the compression test, the simple cubic and gyroid lattice structures' fracture force is higher.
\end{abstract}

Keywords: Lattices. Digital Light Processing (DLP). Bone Tissue Engineering

\section{INTRODUCTION}

With additive manufacturing, which has emerged as a new production method in recent years, it has become possible to manufacture advanced designs. Parts with regular lattice structures in micro size and pores with gradient density can be produced. 3D printers have become a unique manufacturing method to produce lattice structures, thanks to complete control of production parameters, easy creation of complex geometries, and precision processing of small details. High porosity is required for the vascularization, intercellular substance exchange, and lightness in the cancellous bone tissue [1]. Specimens are created with computer-aided design (CAD) to provide porosity and other mechanical properties in a controlled manner. Additive manufacturing; creating micron-sized curves and surfaces, printing the part's details without any problems has enabled the parts to be produced as regular lattice structures $[2,3]$.

Complex geometric features are applied in creating bone tissue. In implants with high rigidity, stress shielding occurs in the contact surface with the bone. Lattices with low rigidity and high strength are used to reduce or eliminate this situation [4]. By combining factors such as tissue growth, osseointegration, material transport, biocompatibility, and biodegradability with mechanical properties, the structures are optimized with the free design brought by additive manufacturing. The behavior of the bone-implant is optimized by applying gradual regional features in the lattice structures. For example, lattices are more durable by designing the inner regions more rigid and the outer regions to be more porous to help bone growth [5]. 
While creating the lattice structures, precise adjustments can be made in structural parameters such as cell topology, cell sizes, and strut thickness. Thus, the material's physical properties can be improved. In forming the lattice structures, the material's physical properties can be improved by making precise adjustments in structural parameters such as cell topology, cell size, and strut thickness. There is an improvement in acoustic, dielectric, and mechanical properties that the primary material does not have. Hence, the part behaves like a metamaterial [6]. In some lattice structures, unit cells created by taking inspiration from nature (biomimetic) are used [7].

Two different porous structures created using gyroid and lattice-based rectangular unit cells; the elastic modulus, compression strength, flow analysis, and wall shear stress, were investigated using the finite element method (FEM). The effect of changing the porosity ratio was observed, and the difference between the lattice structures with constant porosity was compared. It was evaluated which lattice structure would be more suitable for cancellous bone tissue [8]. Metal structures were produced by the Selective Laser Melting (SLM) technique using Regular octet and rhombicuboctahedron unit cells. Geometric defects were detected by X-ray scanning of the specimens. It has been studied to determine the differences in the specimen after design and production. The SLM technique has been brought; nonlinearization in dimension, elastic responses, and error mechanisms has been studied [9]. Four different lattice structures have been subjected to fatigue analysis using the finite element method. The results were compared with the information in the literature. Relative density, fatigue strength, and cell geometry; It has been observed that it affects the power-law function used to predict fatigue [10].

Metal lattice structures created using the gyroid cell were produced by the SLM method. Six different cell sizes between $2 \mathrm{~mm}$ and $8 \mathrm{~mm}$ were examined in terms of density, compression strength, young modulus, and manufacturability. Thanks to the selection of small cell sizes, an increase in density and increased compressive mechanical properties were observed. In the SEM images on the lattice strut surfaces, the adhesion of metal powder particles brought by the SLM technique was observed [11].

By differentiating the volume-centered cubic cells, three different metal lattices were produced by additive manufacturing. The parts with these lattices; Their behaviors against compression, tension, shear, and combined loads were studied. Cell topology and relative density affected the behavior of the parts the most [12].

With Electron Beam Melting (EBM) 3D printing, lattice structures with titanium alloy gyroid and diamond cubic unit cells were produced. It has been observed that reducing the angle between the lattice's support connection struts in the range of $19-68.5^{\circ}$ increases the compressive strength and Young modulus [13].

Metal sandwich panels with body-centered cubic unit cell and octet truss structures are produced with additive manufacturing. Topology optimization processes were performed on the specimens depending on the three-point bending test. Density distribution optimized panels increased stiffness by $46 \%$ compared to uniform panels, and changes in failure modes were observed [14]. With the Direct Laser Writing method, crystal cubic strut lattice and plate lattice structures were produced. Plate lattice structures were three times more rigid under identical mass conditions than strut lattice structures. Some structural features were confirmed by computational analysis as well as empirical analysis [15].

Titanium alloy (Ti-6Al-4V) lattice structures were produced by SLM 3D printing using Schoen Gyroid and Triple Periodic Minimal Surface (TPMS) unit cell. Five different volume ratios between 5\% - 15\%; its effect on elastic modulus and compression strength has been studied both experimentally and by the finite element method. It has been observed that increasing the volume ratio increases the mechanical properties [16]. Triple Periodic Minimal Surface (TPMS) unit cells formed in three groups as skeletal, plate, and strut were examined for their mechanical properties. Plate-based lattice structures showed higher mechanical properties than all other lattice structures. Also, plate-based diamond TPMS displayed a behavior independent of relative density in the view of mechanical performance [17].

The changes of the properties of the specimen 3D printed at different temperatures by using PLA (polylactic acid) material, depending on the printing speed were investigated. The mechanical properties 
in the specimens were found by tensile test and hardness measurement. Different samples were produced in additive manufacturing. Obtaining the tensile strain graph based on the tensile test and comparing the strength values were made [18]. In this study, the production of TCP and HA-doped macroporous structures with various lattices and their mechanical properties were compared.

\section{MATERIAL AND METHOD}

Cylindrical specimens with geometry dimensions of $20 \mathrm{~mm}$ diameter and $10 \mathrm{~mm}$ height were designed. Geometry with a lattice in the inner structure of the parts and a wall of $2 \mathrm{~mm}$ thickness on the lateral outer part is designed. In the finite element analysis, the outer wall was removed to focus only on the lattices, and only the lattice geometries were used. Specialized for forming the lattice structure, adjusting its dimensions, volume; SpaceClaim computer-aided design (CAD) program was used. MeshLab program was used to fix mesh errors and adjust mesh numbers and details. The specimens in Figure 1 were created by using four different unit cells as a gyroid, simple cubic, body-centered cubic, and facecentered cubic as the lattice structure. In all lattice structures, the volume has been chosen to be the same or close to each other. Since the volume is tried to be kept constant, the thickness of the struts is variable. The volume of the lattice structures formed varies between 1625 and $1848 \mathrm{~mm}^{3}$, the porosity rate changes between 41 and $48 \%$ accordingly. The surface area/volume (SA:V) ratio varies between 2.1 and 4.2 , as seen in the column chart in Figure 2.

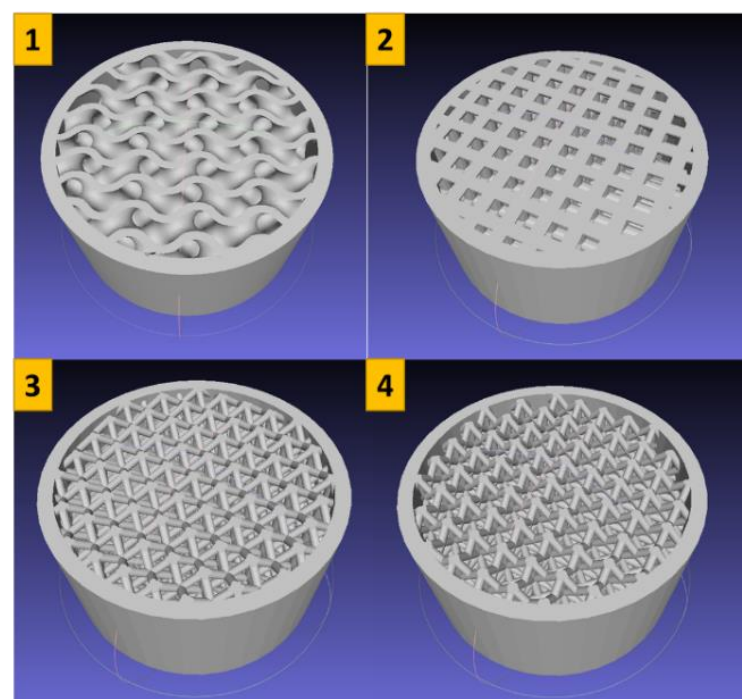

Figure 1. Image of Specimens Designed with Various Lattices: 1) Gyroid, 2) Simple cubic, 3) Volume centered cubic, 4) Face centered cubic.

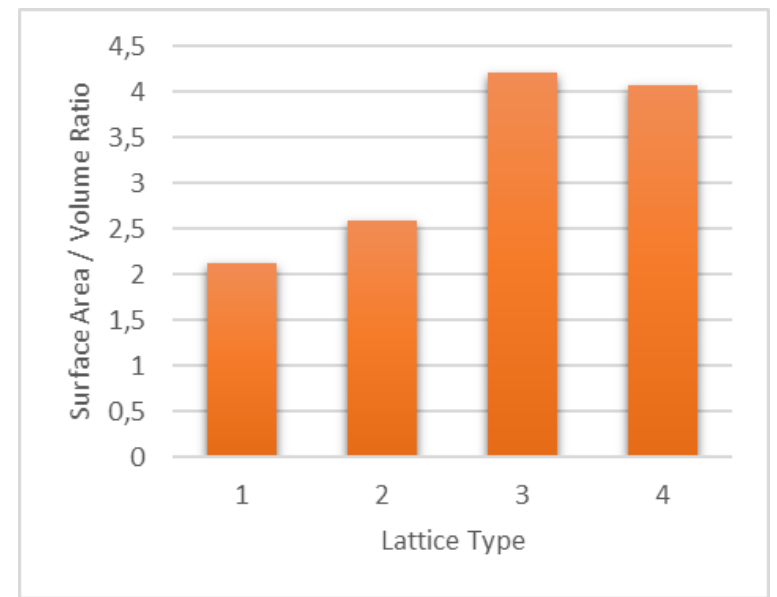

Figure 2. Surface Area to Volume Ratio of Lattice Structures: 1) Gyroid, 2) Simple cubic, 3) Volume centered cubic, 4) Face centered cubic.

The specimens were produced layer by layer with two different additive types using a 3D DLP printer (Novafab Vega). The production steps of the specimens are shown schematically in Figure 3. 
Commercial acrylic-based urethane methacrylate photopolymer resin (Novafab Powerdent Temp) was chosen. As an additive that helps the growth and repair of bones, HA and TCP calcium phosphate powders, which are frequently used in bone tissue engineering, were preferred. The mass ratio of additives added as the powder is $8 \%$. The average diameter of HA powder and TCP powder particles were $15 \mu \mathrm{m}$ and $5 \mu \mathrm{m}$ in size, respectively. The resins were mixed in a mechanical stirrer at $1000 \mathrm{rpm}$ for 15 minutes. Then the resin mixture was poured onto the vat of the 3D DLP printer. After printing, specimens were washed with ethanol several times and dried. The specimens were ultraviolet cured and not sintered.

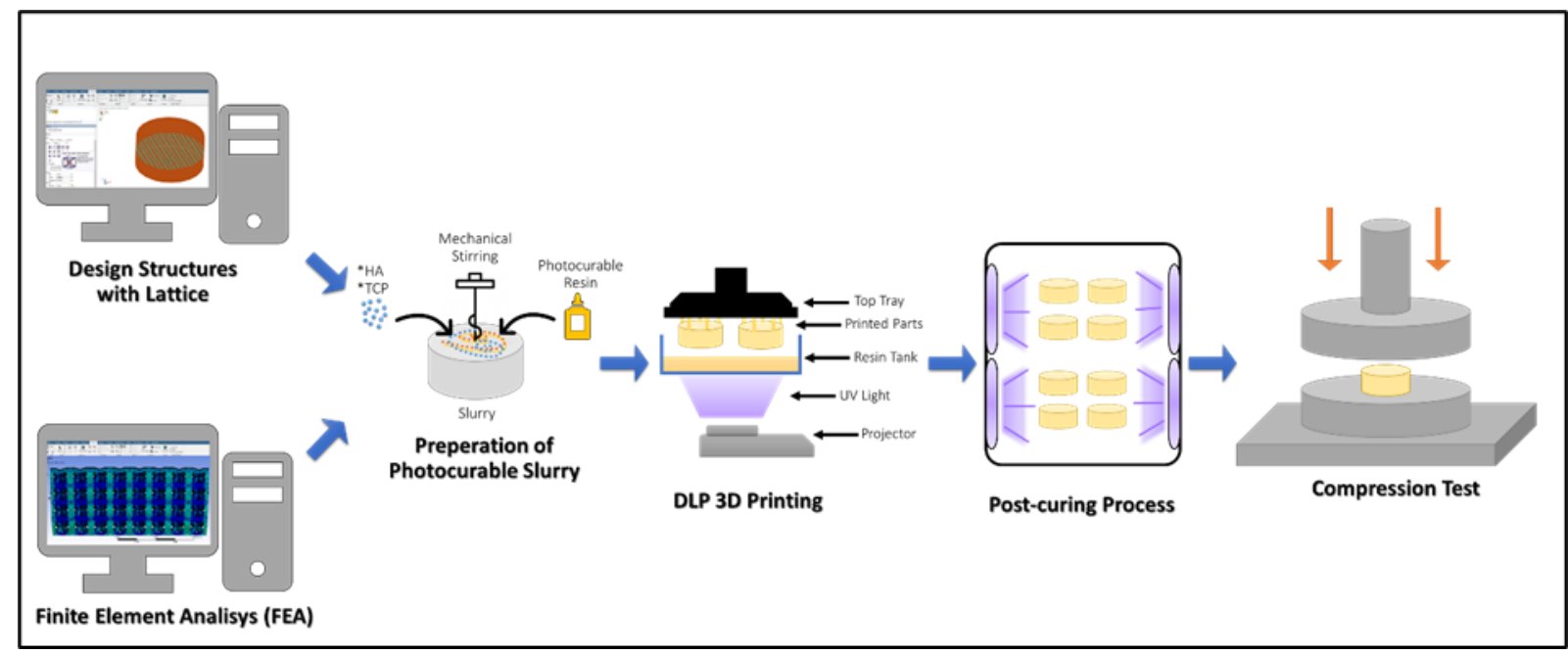

Figure 3. Flow Chart Showing the Production Processes of Specimens.

Specimens are named with a 4-digit coding, as shown in the example in Figure 4. It belongs to first digit compression test, second digit lattice structure type (1: gyroid, 2: simple cubic, 3: volume centered cubic, 4: face-centered cubic), third digit resin type (a: undoped resin, b: HA doped resin, c: TCP doped resin), the 4 th digit indicates the number of repetitions of the same specimen.

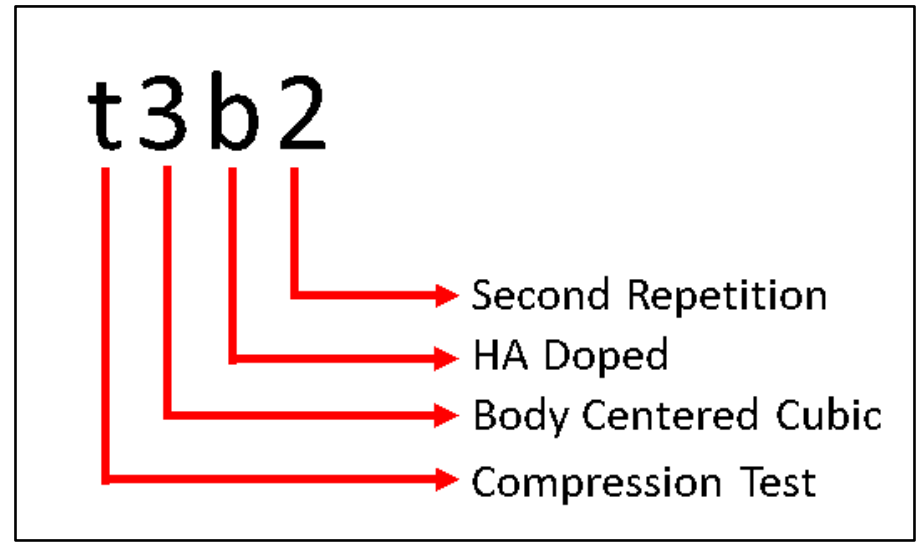

Figure 4. Explanation of Specimen Coding.

The lattice structures were preliminarily evaluated in terms of structural strength using the finite element method. Fixed support to the lower surface of the geometry and $500 \mathrm{~N}$ force perpendicular to the upper surface from top to bottom; boundary conditions are given. The resin epoxy material has been assigned to the part, which has mechanical properties close to photopolymer resin and has predefined mechanical properties (young modulus $3.78 \mathrm{GPa}$, bulk modulus $4.2 \mathrm{GPa}$, shear modulus $1.4 \mathrm{kPa}$, Poisson's ratio 0.35). Different mesh creation methods have been tried according to the geometry of the lattice structures. The distance between the nodes is inputted as $0.3 \mathrm{~mm}$ for all types of the lattice structure. The directional deformation results, total deformation, compressive stress, and von-Mises stress are defined as calculation output. Before the specimens were taken to the compression test, they were sanded 
from the lower and upper surfaces to remove the roughness. All the specimens were preloaded with 250 $\mathrm{N}$ prior to the test. The speed of the crosshead was $1 \mathrm{~mm} / \mathrm{s}$.

TCP and HA substances were added to the specimens in order to bring the bioactivity feature. The bioactivity test was carried out in another study to measure the success of the specimens produced with different lattice in activities such as adhesion, growth and heal in bone tissue. According to the results of this study, it has been shown that the specimens show bioactive reactions and can be used in bone tissue applications [19].

\section{EXPERIMENTAL RESULTS}

\subsection{Finite Element Method Structural Analysis Results}

It is seen in Figure 5 and Figure 6 that the highest deformation and stress regions are in the edge regions and the incomplete regions of the struts for each type of lattice structure. In a structure that is integrated with an outer wall, it is assumed that these regions will not take maximum values. For this reason, the maximum values outside of these regions were scanned with the probe. The graphics in Figures 7 and 8 were created according to the probe's highest values.

While the total deformation in the lattice structures is highest in the upper parts, the total deformation is the lowest in the lower parts with fixed support, as in Figure 5. It can be seen that the von-Mises stress is concentrated along the vertical supporting struts in the simple cubic structure. However, in Figure 6, the von-Mises stress is more dispersed on the gyroid structure's surface. In the body-centered cubic and face-centered cubic structure, regular stress regions are observed in the areas where vertical struts bear loads.

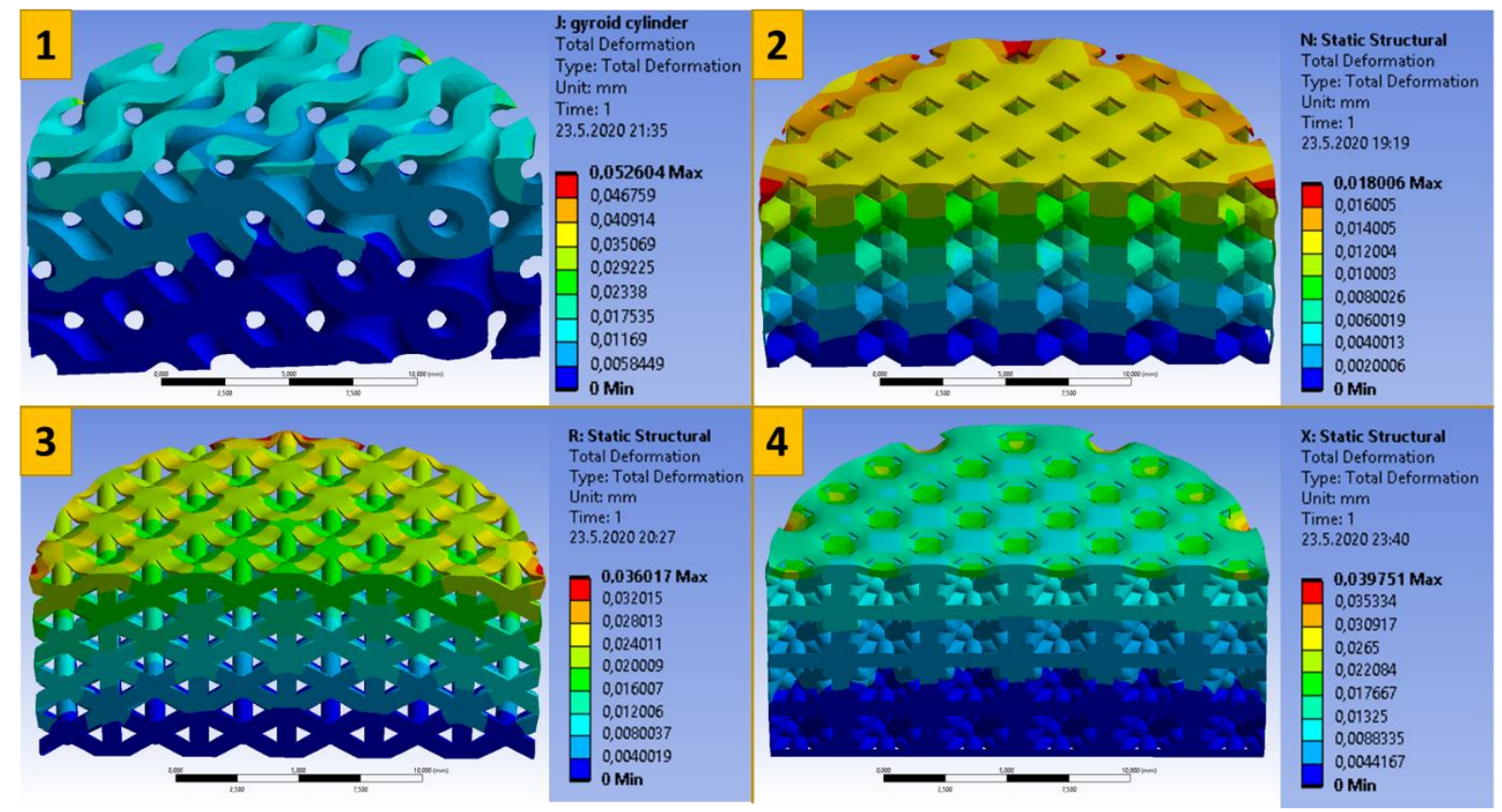

Figure 5. Total Deformation Values of Lattice Structures: 1) Gyroid, 2) Simple cubic, 3) Volume centered cubic, 4) Face centered cubic. 


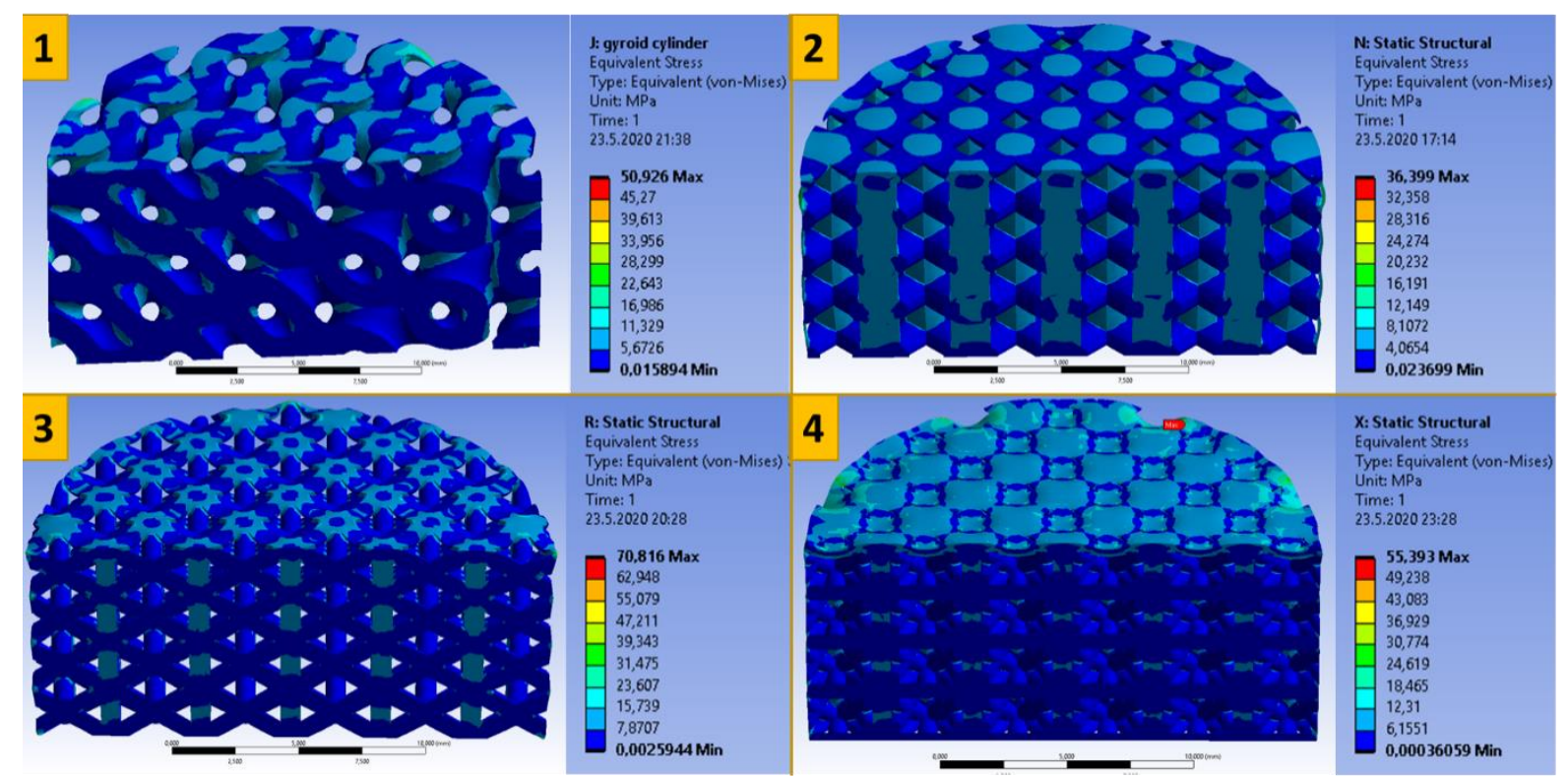

Figure 6. Von-Mises Stress Values of Lattice Structures: 1) Gyroid, 2) Simple cubic, 3) Volume centered cubic, 4) Face centered cubic.

Among the lattice structures, the slightest deformation is in the simple cubic structure, and its value is $0.013 \mathrm{~mm}$. Then gyroid, face-centered cubic, and body-centered cubic lattice structure follow, respectively. Deformation values are shown in Figure 7. The minimal difference between axial and total deformation values is since the load is only in the y-direction.

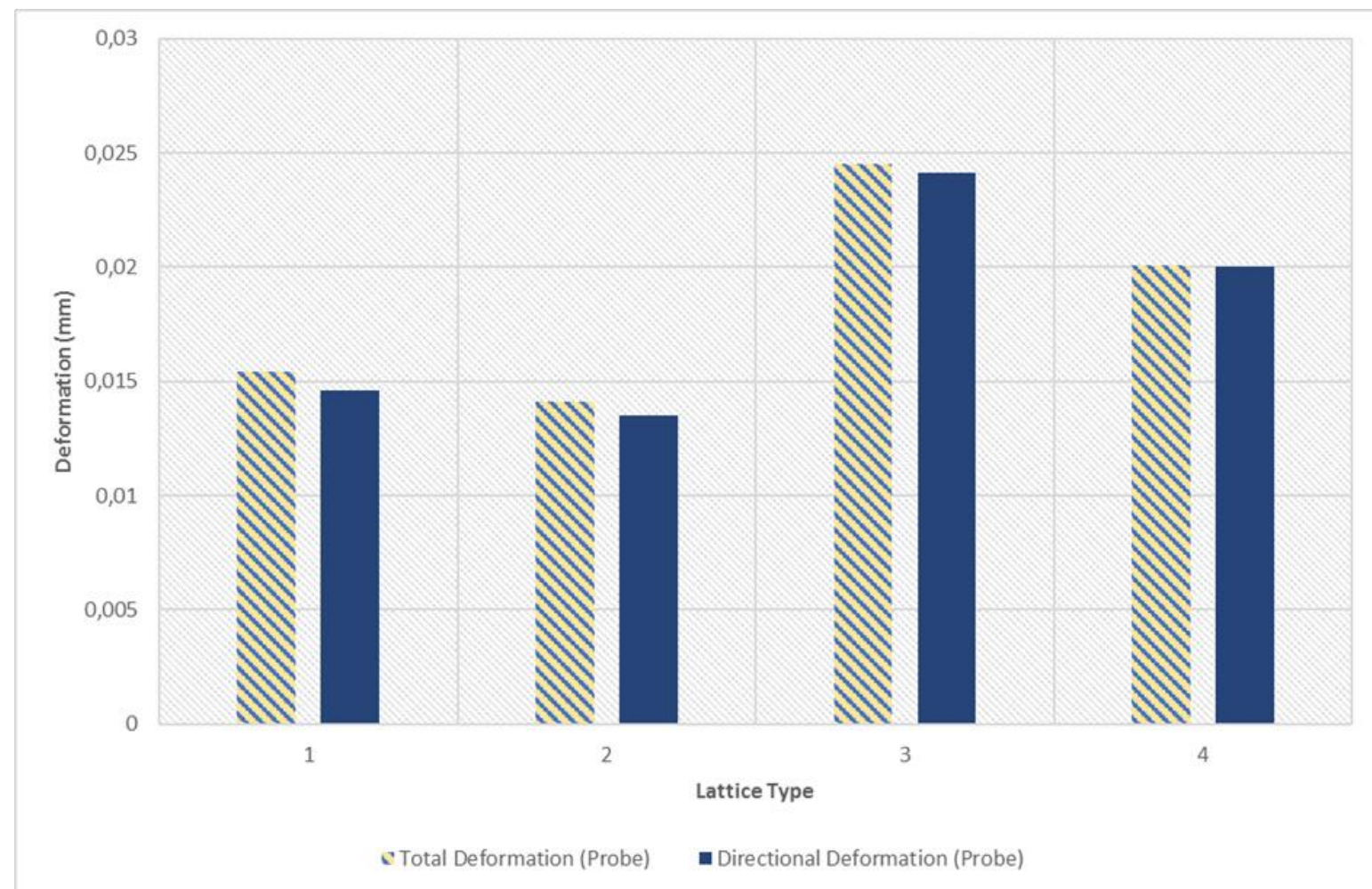

Figure 7. Deformation Values of Lattice Structures: 1) Gyroid, 2) Simple cubic, 3) Volume centered cubic, 4) Face centered cubic.

Among the lattice structures, the minimum von mises stress value is in the simple cubic lattice structure, and its value is 5.861 MPa. The von-Mises stress value, then the face-centered cubic, gyroid, and the most body-centered cubic lattice, respectively, can be seen in Figure 8. It has been observed that the stress zones are at the joints of the struts and in sharp regions. 


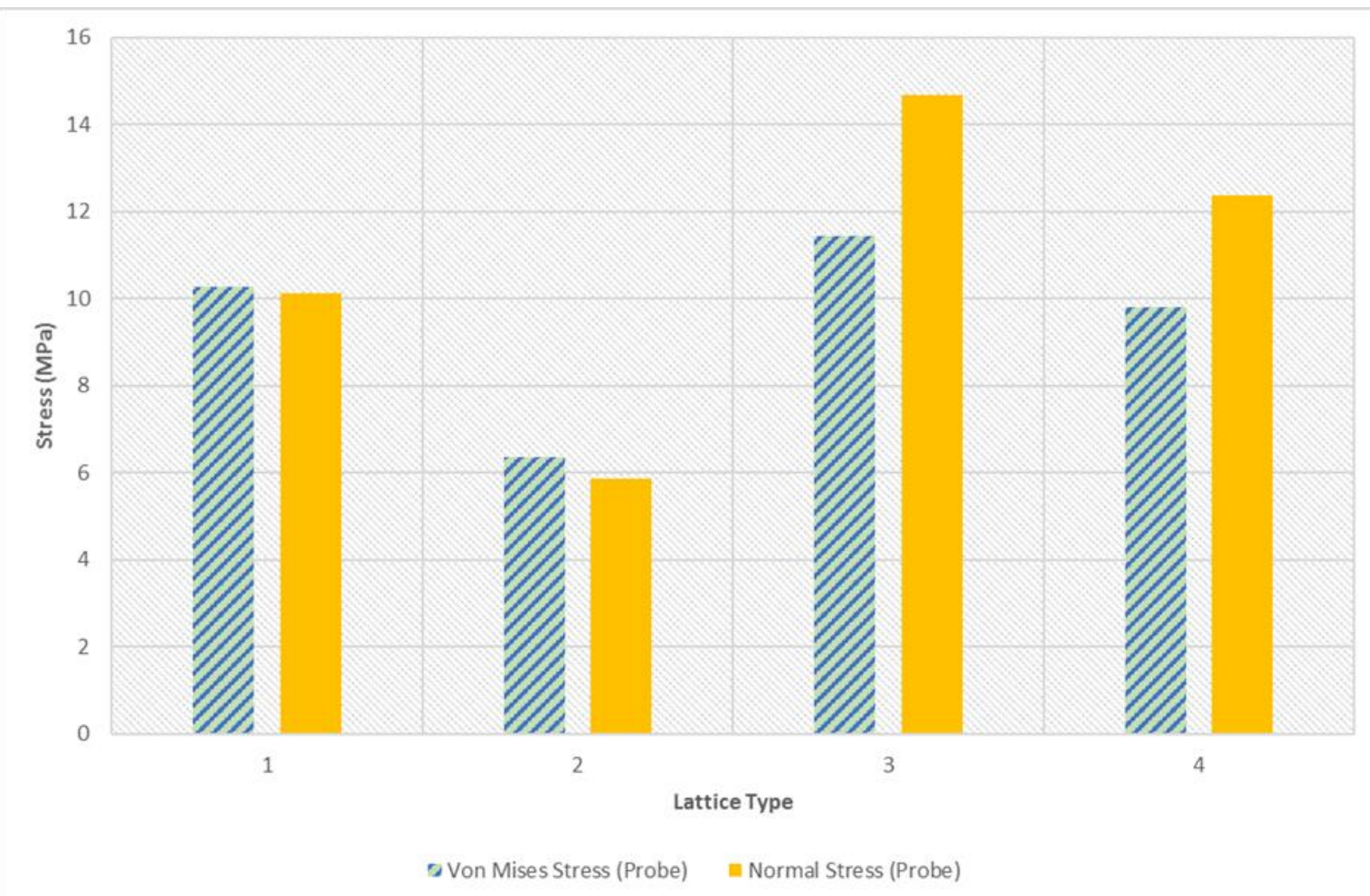

Figure 8. Stress Values of Lattice Structures: 1) Gyroid, 2) Simple cubic, 3) Volume centered cubic, 4) Face centered cubic.

\subsection{Compression Test Results}

Among the specimens, the highest pre-fracture force occurs in the surface-centered cubic lattice structure made of undoped resin, and its value is $12.36 \mathrm{kN}$. The lowest force occurs in the face-centered cubic lattice structure with HA doped. HA doped, volume-centered, and face-centered cubic structures were below the average, as seen in Figure 9. While each of the undoped resin specimens is above $7 \mathrm{kN}$, there are specimens below $7 \mathrm{kN}$ in surface and volume centered cubic lattice structures in HA and TCP doped specimens.

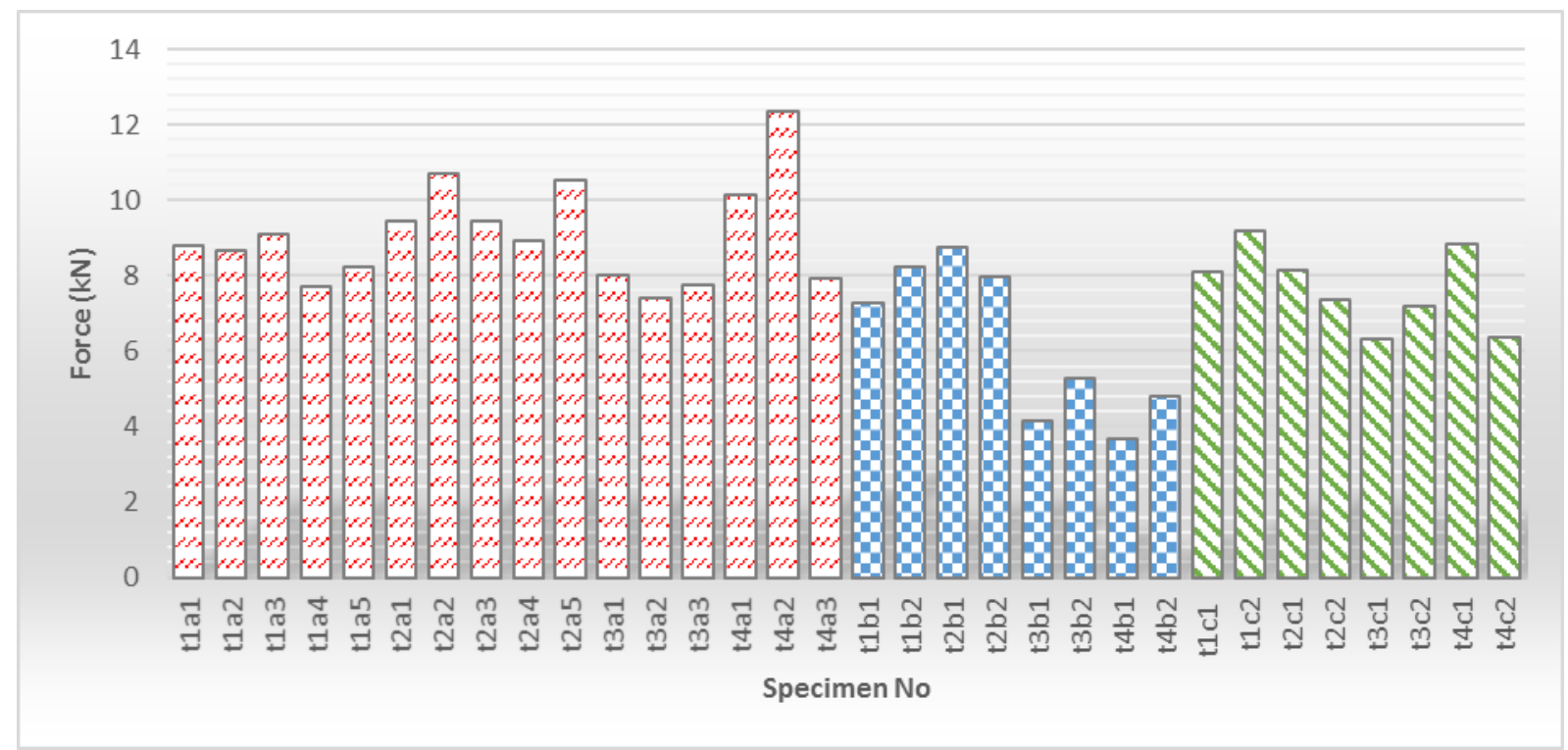

Figure 9. Pre-Fracture Force Values in Compression Test of Specimens. 
The average and standard deviations of the specimens with the same resin type and the same lattice structure are shown with error bars in the graphic in Figure 10. It was observed that the highest force was in the undoped resin surface-centered lattice structure, and at the same time, this value had the highest standard deviation. Since the magnitude of the standard deviation decreases the reliability of the data, alternative values were examined. The second highest force value was observed in the simple cubic lattice structure. Besides, this value's low standard deviation showed a more reliable result than the first one.

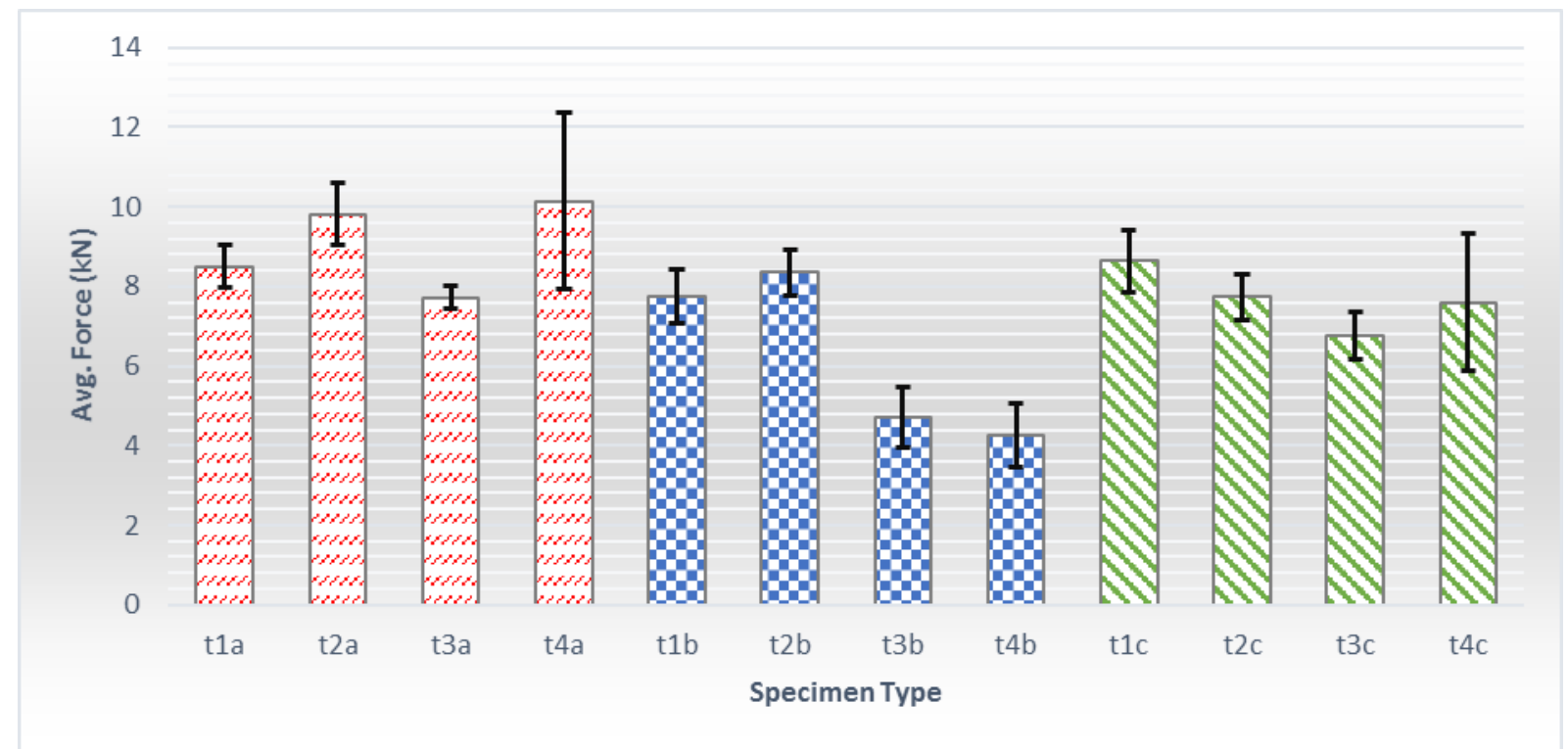

Figure 10. Average Values of Pre-Fracture Loads in the Compression Test of Specimens.

In order to compare the compressive strength in lattice structures, specimens made of undoped resin were evaluated. The face-centered cubic lattice structure has been ignored due to its low reliability. Accordingly, it has been seen that the simple cubic lattice structure gives a higher result than the others. When the lattice structures were examined according to resin types, it was seen that the specimens with undoped resin were generally higher than the specimens with doped resin.

The specimens with identical lattices with undoped resin are brought together in the force-displacement graph in Figure 11. It is observed that the most suitable lattice structure for gradual fracture is in specimens with simple cubic lattice with slight decreases in the curve. It is seen that the difference between the pre-fracture load values of the face-centered lattice structures is high. The second and fifth specimens with simple cubic lattice have an average of 10 to $15 \%$ higher pre-fracture load and $25 \%$ more displacement than the other specimens. Apart from this, the specimens' fracture mechanism in the same lattice structures was generally similar to each other. In all lattice structures, fracture occurred when the displacement was between 1 and $1.5 \mathrm{~mm}$. Surface-centered cubic lattice specimens continue to compress without a sudden drop on the curve; It is thought to be since it is produced by curing too much, including pores. 


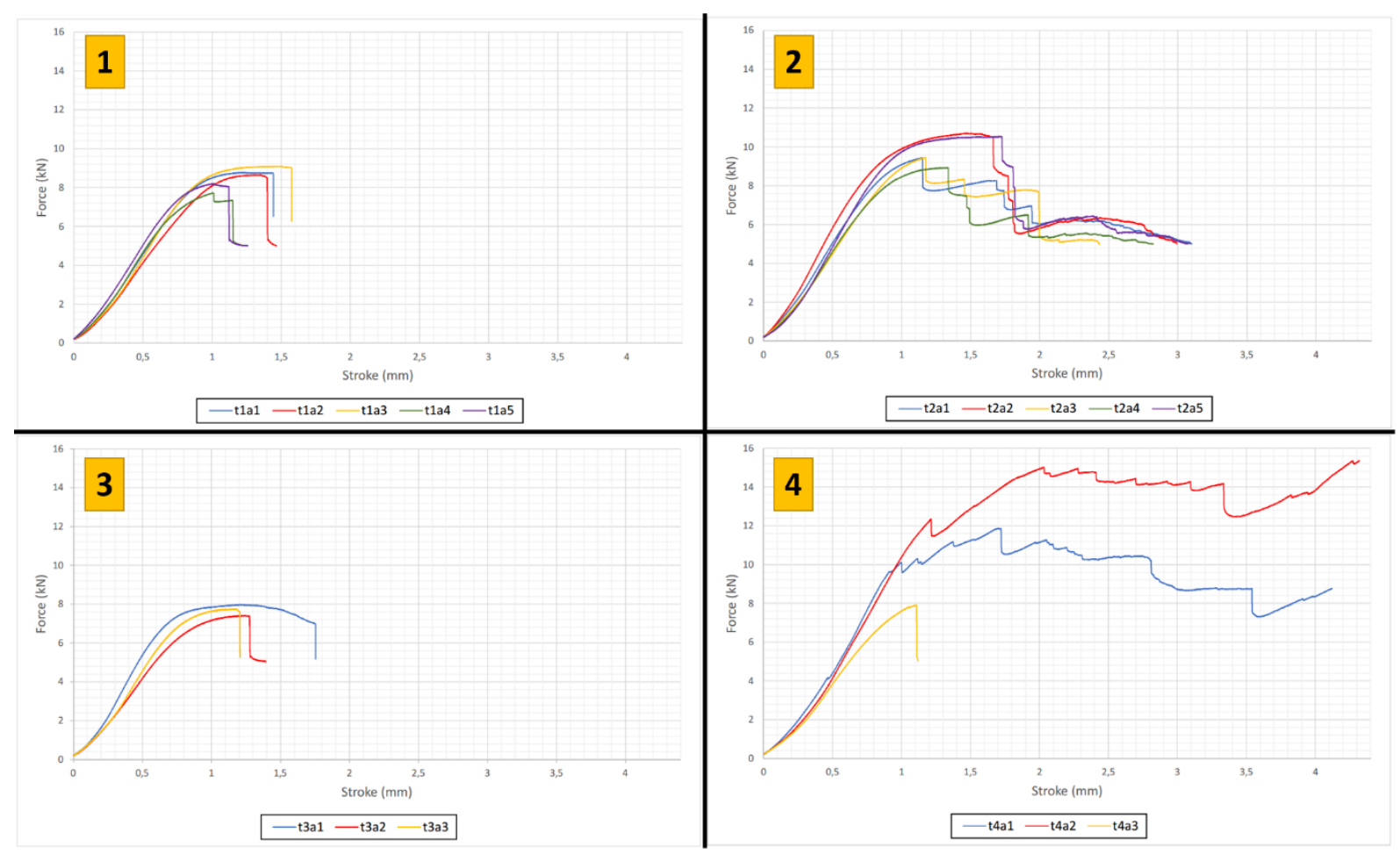

Figure 11. Permanent Deformation Image of Simple Cubic Lattice Structure After Compression Test.

In the entire compression test specimens, the first moment of breaking started with breaking the outer wall, as shown in Figure 11. In some specimens, breaking the outer wall caused either a sudden or a gradual decrease due to lattice structures. The simple cubic lattice specimen with damaged outer wall is shown in Figure 12. The mechanical properties of the t4a2 specimen, which has the highest compression strength, were found according to the cross-sectional area calculated approximately. Accordingly, the compressive strength of the specimen was calculated as $80.3 \mathrm{MPa}$, elasticity module as $1.99 \mathrm{MPa}$, and resilience as $493.8 \mathrm{MJ} / \mathrm{m}^{3}$.

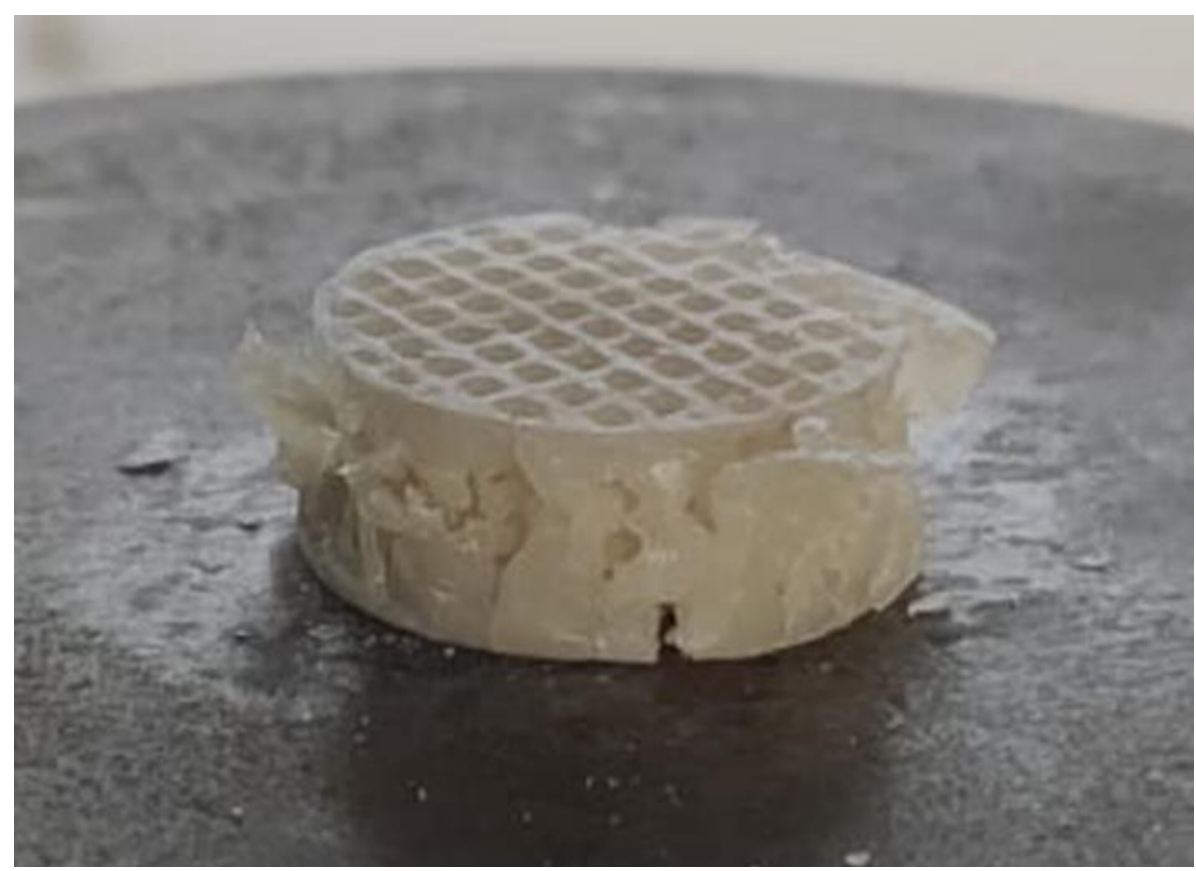

Figure 12. Permanent Deformation Image of Undoped Simple Cubic Lattice Structure (t2a) After Compression Test [20]. 


\section{CONLUSION}

A quasi-static compression test was applied to the specimens successfully produced from powder-doped resin with the 3D DLP method. The highest force value was the face-centered cubic lattice structure produced from undoped resin with $12.4 \mathrm{kN}$ among the specimens. Force values were averaged according to the repeated compression test applied to specimens of the same type. The specimen with a low standard deviation and the highest force value is an undoped resin simple cubic lattice specimen. When the specimens with low standard deviation were evaluated, it was seen that simple cubic and gyroid lattice structures generally showed higher forces. When lattice structures designed with the same or close volume values are evaluated in terms of $\mathrm{SA}: \mathrm{V}$ ratio, volume-centered cubic and face-centered cubic lattice structures were superior.

It has been observed that the doping of powder additives to the resin primarily reduces the pre-fracture force. A sintering process is required to increase the compression strength in specimens with high ceramic additives. It can also be argued that the high standard deviation in some samples is caused by excessive solidification in the lattice structures or incomplete solidification in the struts. The high standard deviation in some specimens indicates over-solidification between the pores in the lattice structures or under-solidification of the struts.

For the test results in the lattice structures to be reliable and significant, the geometry size should be increased. With the growth of dimensions, the residual resin removal would be proper, and the pore geometries would be better produced. Thus, specimens will be printed with a minor error. The results will be more reliable with similar values in repetitive specimens of the same type. Besides, increasing the specimen's repetition in the compression test will increase the test result's reliability.

It is thought that testing different types of additives, designing different lattice structures, applying different tests to the lattice structures, and applying different processes before or after printing will be a suitable subject for future studies.

\section{ACKNOWLEDGMENT}

This study is a part of a Master's Thesis carried out by Muhammed Enes DOKUZ at Necmettin Erbakan University, Institute of Science. Mesut UYANER and Mustafa AYDIN are the advisors of this thesis. This research was financially supported by Necmettin Erbakan University Scientific Research Projects Coordinatorship (Grant no. 191319013). Also, we wish to thank Kutahya Dumlupınar University Advanced Research Center (ILTEM) for facilitating laboratories, devices, and equipment.

Marmara University Metallurgy and Materials Engineering Department member Dr. Oğuzhan Gündüz provided us TCP powder used in this study. The authors especially thank him for their valuable contribution to their study.

\section{REFERENCES}

1. Jodati, H., Yılmaz, B., Evis, Z., "A review of bioceramic porous scaffolds for hard tissue applications: Effects of structural features”, Ceram. Int., Vol. 46, Issue 10, Pages 15725-15739, 2020.

2. Afshar, M., Pourkamali Anaraki, A., Montazerian, H., "Compressive characteristics of radially graded porosity scaffolds architectured with minimal surfaces”, Mater. Sci. Eng. C, Vol. 92, Pages 254-267, 2018.

3. Chen, Z., Li, Z., Li, J., Liu, C., Lao, C., Fu, Y., Liu, C., Li, Y., Wang, P., He, Y., “3D printing of ceramics: A review", J. Eur. Ceram. Soc., Vol. 39, Issue 4, Pages 661-687, 2019.

4. Zaharin, H.A., Rani, A.M.A., Azam, F.I., Ginta, T.L., Sallih, N., Ahmad, A., Yunus, N.A., Zulkifli, T.Z.A., "Effect of unit cell type and pore size on porosity and mechanical behavior of additively manufactured Ti6Al4V scaffolds", Materials (Basel), Vol. 11, Issue 12, Page 2402, 2018.

5. Ngo, T.D., Kashani, A., Imbalzano, G., Nguyen, K.T.Q., Hui, D., “Additive manufacturing (3D printing): A review of materials, methods, applications and challenges", Compos. Part B Eng., Vol. 143, Pages 172-196, 2018. 
6. Maconachie, T., Leary, M., Lozanovski, B., Zhang, X., Qian, M., Faruque, O., Brandt, M., "SLM lattice structures: Properties, performance, applications and challenges”, Mater. Des., Vol. 183, Page 108137, 2019.

7. Plessis, A., Broeckhoven, C., Yadroitsava, I., Yadroitsev I, Hands, C.H., Kunju, R., Bhate, D., "Beautiful and functional: a review of biomimetic design in additive manufacturing", Addit. Manuf., Vol. 27, Pages 408-427, 2019.

8. Ali, D., Sen, S., "Finite element analysis of mechanical behavior, permeability and fluid induced wall shear stress of high porosity scaffolds with gyroid and lattice-based architectures", J. Mech. Behav. Biomed. Mater., Vol. 75, Pages 262-270, 2017.

9. Liu, L., Kamm, P., García-Moreno, F., Banhart, J., Pasini D., "Elastic and failure response of imperfect threedimensional metallic lattices: the role of geometric defects induced by Selective Laser Melting", J. Mech. Phys. Solids, Elsevier Ltd, Vol. 107, Pages 160-184, 2017.

10. Zargarian, A., Esfahanian, M., Kadkhodapour, J., Ziaei-Rad, S., Zamani, D., "On the fatigue behavior of additive manufactured lattice structures”, Theor. Appl. Fract. Mech., Elsevier B.V., Vol. 100, Pages 225$232,2019$.

11. Yan, C., Hao, L., Hussein, A., Raymont, D., "Evaluations of cellular lattice structures manufactured using selective laser melting”, Int. J. Mach. Tools Manuf., Vol. 62, Pages 32-38, 2012.

12. Gümrük, R., Mines, R.A.W., Karadeniz, S., "Static mechanical behaviours of stainless steel micro-lattice structures under different loading conditions”, Mater. Sci. Eng. A, Vol. 586, Pages 392-406, 2013.

13. Yánez, A., Herrera, A., Martel, O., Monopoli, D., Afonso, H., "Compressive behaviour of gyroid lattice structures for human cancellous bone implant applications”, Mater. Sci. Eng. C, Vol. 68, Pages 445-448, 2016.

14. Kang, D., Park, S., Son, Y., Yeon, S., Kim, S.H., Kim, I., "Multi-lattice inner structures for high-strength and light-weight in metal selective laser melting process", Mater. Des., Vol. 175, Page 107786, 2019.

15. Tancogne-Dejean, T., Diamantopoulou, M., Gorji, M.B., Bonatti, C., Mohr, D., “3D plate-lattices: An emerging class of low-density metamaterial exhibiting optimal isotropic stiffness", Adv. Mater., Vol. 30, Issue 45, Pages 1-6, 2018.

16. Yang L., Yan, C., Han, C., Chen, P., Yang, S., Shi, Y., "Mechanical response of a triply periodic minimal surface cellular structures manufactured by selective laser melting”, Int. J. Mech. Sci., Vol 148, Pages 149157, 2017.

17. Al-Ketan, O., Rowshan, R., Abu Al-Rub, R.K., "Topology-mechanical property relationship of 3D printed strut, skeletal, and sheet based periodic metallic cellular materials", Addit. Manuf., Vol. 19, Pages 167-183, 2018.

18. Aydın, M., Yıldırım, F., Çantı, E., "Farklı yazdırma parametrelerinde PLA filamentin işlem performansının incelenmesi", 4th International Congress on 3D Printing (Additive Manufacturing) Technologies and Digital Industry, Pages 102-115, Antalya, 2019.

19. Dokuz, M.E., Aydın, M., Uyaner, M., "Production of bioactive various lattices as an artificial bone tissue by digital light processing 3D printing", Journal of Materials Engineering and Performance, https://doi.org/10.1007/s11665-021-06067-7, 2021.

20. Dokuz, M.E., “3 Boyutlu DLP yöntemiyle HA katkılı kompozit üretimi ve karakterizasyonu”, M.Sc. thesis, [HA doped composite production by 3 dimensional DLP method and characterization] [Thesis in Turkish], Konya Necmettin Erbakan Üniversitesi, Konya, 2020. 